\title{
O uso de mídias digitais, associados ao ambiente virtual de ensino e de aprendizagem, no ensino de química: explorando a radioatividade por meio da educação a distância
}

Maurício Severo da Silva mss@universo.univates.br 0000-0003-1271-6981

Universidade do Vale do Taquari Univates, Lajeado, Rio Grande do Sul, Brasil.

Katiele Stefani Zotti katyszotti@gmail.com 0000-0001-9446-927X

Universidade do Vale do Taquari Univates, Lajeado, Rio Grande do Sul, Brasil.

Marcia Jussara Hepp Rehfeldt mrehfeld@univates.br 0000-0002-0007-8639

Universidade do Vale do Taquari Univates, Lajeado, Rio Grande do Sul, Brasil.

Miriam Ines March

mimarchi@univates.br

0000-0003-2546-7072

Universidade do Vale do Taquari Univates, Lajeado, Rio Grande do

Sul, Brasil.

\section{RESUMO}

O presente texto é um relato de experiência que teve como objetivo possibilitar aos estudantes de uma turma do 10 ano do Ensino Médio o estudo do tema radiação por meio do Ambiente Virtual de Ensino e de Aprendizagem. Os professores organizaram sua prática pedagógica em seis encontros, um presencial e os seguintes a distância. Os docentes utilizaram mídias digitais, tais como: animações, vídeos, textos, infográficos e o jogo comercial SimCity, bem como uma ferramenta de comunicação e interação, o fórum de discussão, presente no AVEA. Este recurso possibilitou que os estudantes interagissem entre si, proporcionando ricas e acaloradas discussões. No entanto, o jogo SimCity foi o que provocou maior engajamento entre o grupo de alunos. Como forma de avaliação, os docentes solicitaram que os estudantes se organizassem em grupos para gravar um vídeo, no qual os discentes deveriam demonstrar o que aprenderam sobre os assuntos abordados. A qualidade do conteúdo e da produção apresentada pelos estudantes surpreendeu os docentes e evidenciou a preferência dos alunos por este tipo de atividade. Os docentes acreditam que o uso de forma estratégica do AVEA e das mídias digitais, em conjunto com atividades que possibilitaram aos discentes serem autores de suas próprias discussões, reflexões e vídeos, auxiliou no desenvolvimento de uma postura mais proativa dos alunos e de uma maior autonomia nos seus estudos.

PALAVRAS-CHAVE: Relato de experiência. Prática pedagógica. Ensino à distância. Ambiente virtual de ensino e de aprendizagem. Mídias digitais. 


\section{INTRODUÇÃO}

A inserção de mídias digitais no ensino vem sendo discutida e estudada por diversos autores, tais como Saeed (2010) e Leite (2016). Contudo, estes mesmos autores concordam que é difícil para um docente que não possui uma formação voltada ao uso de tecnologias educacionais - ou não as utilizou durante sua formação - inseri-las em suas práticas pedagógicas. Isso ocorre por diversos fatores, como a falta de habilidade com o uso de tecnologias digitais, desconhecimento quanto aos recursos disponíveis, a falta de tempo para planejar o uso de mídias digitais em sala de aula, entre outros.

Além destes fatores, Prensky (2001) apresenta uma reflexão que agrega outro motivo às dificuldades dos docentes em adicionar mídias digitais em suas práticas pedagógicas. $\mathrm{O}$ autor argumenta que o distanciamento geracional existente entre os professores que nasceram em uma época onde pouca ou quase nenhuma tecnologia digital era existente amplia as dificuldades de diálogo com as novas gerações, que já nasceram imersas em um mundo onde a comunicação e a interação são cada vez mais digitais. Para Prensky (2001), os docentes nascidos e formados na era pré-digital foram ensinados que o professor é o meio de informação mais substancial que deve haver na formação de um indivíduo, sendo o detentor do conhecimento, condição esta que não é mais válida em tempos atuais. Diante disso, o autor destaca que o abismo geracional entre os que nasceram antes e após as tecnologias digitais é tão grande que parecem conversar em diferentes idiomas.

Com base nisso, é possível perceber que um docente que não acompanha a evolução das tecnologias e não atualiza suas práticas pedagógicas está distanciando-se ainda mais da realidade dos atuais estudantes. Um estudo recente publicado pelo Cetic.br ${ }^{1}$ (2016) demonstra que o número de dispositivos capazes de acessar a Internet disponíveis aos estudantes cresce a cada dia. Segundo o relatório, 89\% dos estudantes entre 15 e 17 anos, de escolas públicas, utilizam meios de acesso à Internet como instrumentos para efetuarem pesquisas escolares, número este que chega a $97 \%$ no ensino privado. Vale destacar que o relatório não deixa claro se os estudantes utilizam a Internet a pedido dos docentes ou se a buscam de forma espontânea.

Já, ao contrário, docentes que buscam inserir as tecnologias, por meio do uso de mídias digitais, em suas práticas tendem a tornar as atividades de ensino e de aprendizagem mais atraentes aos estudantes. Nesse sentido, Santos et al. (2016) afirmam que os Ambientes Virtuais de Aprendizagem (AVAs) constituem-se em espaços fecundos que podem ser utilizados para promover a comunicação e interatividade, além de serem capazes de potencializar os processos de ensino e de aprendizagem. Neste trabalho, os docentes optaram pela utilização do Ambiente Virtual de Ensino e Aprendizagem (AVEA) como instrumento de comunicação, interação e disponibilização de mídias digitais coletadas na Internet e, também, produzidas pelos professores.

É importante destacar que tanto o uso de AVEAs quanto de mídias digitais no ensino não resolve os problemas de aprendizagem dos estudantes. Sendo assim, mesmo as atividades que utilizam tais recursos necessitam de planejamento e de objetivos pedagógicos claramente definidos. Isso porque, sem estas etapas, o docente corre o risco de reduzir o potencial destes recursos a meros artifícios para deixar a aula mais divertida, conforme argumenta Demo (2016). 
Quanto a isto, Lames (2011) afirma que o docente precisa refletir sobre sua prática pedagógica de modo a superar o uso inadequado das tecnologias. Os docentes precisam compreender o que é aprender e o que é ensinar para que, assim, possam criar e oportunizar aos discentes novas metodologias de ensino, "de produzir, comunicar e representar o conhecimento" (LAMES, 2011, p. 23), o que, segundo a autora, é possibilitado pelas novas mídias.

Foi com base na reflexão sugerida por Demo (2016) e Lames (2011) que os docentes e autores deste trabalho chegaram a seguinte questão de pesquisa: quais os efeitos pedagógicos do uso de um Ambiente Virtual de Ensino e de Aprendizagem, associado a conteúdos que explorem diferentes mídias digitais, e da educação a distância, no ensino do tema radioatividade em uma turma de 1o ano do Ensino Médio?

Tendo em vista a questão norteadora, os docentes efetuaram o planejamento de suas atividades, de modo a propiciar a seus discentes uma experiência no uso de diversos tipos de mídias digitais, que puderam ser acessadas por meio de um Ambiente Virtual de Ensino e de Aprendizagem. Posto isso, a pesquisa teve como objetivo desvelar os efeitos de diferentes mídias digitais por meio de um Ambiente Virtual de Ensino e Aprendizagem, com discentes do 1ㅇano do Ensino Médio, na disciplina de Química. Como forma de fundamentar a prática realizada, a seção a seguir apresenta um breve resumo da abordagem teórica que guiou os docentes durante a escolha das ferramentas e tipos de mídias a serem utilizadas. Na sequência, a seção 3 apresenta as particularidades da metodologia adotada pelos docentes, bem como o detalhamento da prática efetivada. Por fim, são apresentados os resultados obtidos e as considerações finais.

\section{ABORDAGEM TEÓRICA}

De acordo com Messa (2010), os AVEAs estão sendo cada vez mais utilizados no âmbito educacional, uma vez que permitem o uso de mídias para veicular conteúdos e possibilitam a interação por meio de suas ferramentas, fornecendo suporte a diversos tipos de atividades propostas aos alunos. Diante disso, é preciso elucidar que a prática pedagógica apresentada neste relato foi planejada de modo a aproveitar os recursos que o AVEA Moodle disponibiliza. Sendo assim, neste trabalho, a abordagem teórica objetiva situar o leitor quanto a alguns dos conceitos utilizados pelos docentes durante o planejamento e efetivação da prática pedagógica, que usou as mídias digitais com o apoio do Ambiente Virtual.

Como forma de elucidar todos os recursos utilizados pelos docentes, cabe, neste momento, apresentar o Quadro 1, onde estão listados os recursos do AVEA, os tipos de mídias digitais de que os docentes se beneficiaram, bem como o objetivo de cada um destes instrumentos. 
Quadro 1 - Recursos do AVEA e mídias digitais utilizadas

\begin{tabular}{|c|c|c|}
\hline \multicolumn{2}{|l|}{ Recurso } & Objetivos \\
\hline \multirow{4}{*}{$\begin{array}{l}\text { Ferrament } \\
\text { as do } \\
\text { AVEA }\end{array}$} & Fórum & $\begin{array}{l}\text { - Promover a comunicação; } \\
\text { - Realizar postagem de atividades; } \\
\text { - Proporcionar discussões acerca dos temas estudados. }\end{array}$ \\
\hline & E-mail & - Promover a comunicação. \\
\hline & Livro & - Elaborar roteiros de estudos. \\
\hline & Rótulo & $\begin{array}{l}\text { - Orientar os estudantes quanto às atividades a serem } \\
\text { desenvolvidas. }\end{array}$ \\
\hline \multirow{6}{*}{$\begin{array}{l}\text { Mídias } \\
\text { Digitais }\end{array}$} & $\begin{array}{l}\text { Hipertexto } \\
\text { (Roteiros de } \\
\text { Estudo) }\end{array}$ & $\begin{array}{l}\text { - Guiar o estudante por meio dos diversos tipos de } \\
\text { mídia previamente selecionados pelos docentes. }\end{array}$ \\
\hline & $\begin{array}{l}\text { Textos } \\
\text { informativos }\end{array}$ & - Servir de material base para os estudos individuais. \\
\hline & Infográficos & $\begin{array}{l}\text { - Apresentar informações e dados de forma visual, com } \\
\text { o objetivo de ampliar a compreensão do tema em } \\
\text { estudo. }\end{array}$ \\
\hline & Vídeos & $\begin{array}{l}\text { - Servir de material base para os estudos individuais; } \\
\text { - Estimular a reflexão sobre o tema em estudo; } \\
\text { - Buscar indícios do aprendizado dos estudantes. }\end{array}$ \\
\hline & $\begin{array}{l}\text { Animação } \\
\text { interativa }\end{array}$ & $\begin{array}{l}\text { - Aproximar o estudante de uma realidade fictícia, } \\
\text { possibilitando-Ihe interagir e observar os efeitos de } \\
\text { suas ações no ambiente. }\end{array}$ \\
\hline & Jogo (SimCity) & $\begin{array}{l}\text { - Aproximar o estudante de uma realidade fictícia, } \\
\text { possibilitando-lhe interagir e observar os efeitos de } \\
\text { suas ações no ambiente; } \\
\text { - Estimular a reflexão sobre as verdades, mentiras e } \\
\text { adaptações da realidade promovida nos jogos digitais. }\end{array}$ \\
\hline
\end{tabular}

(Fonte: Elaborado pelos autores com base em (MORAN, 1995; MACIEL et al, 2012; CUNHA; PAIVA, 2003; TRINDADE; REHFELDT; MARCHI, 2016; MÓDOLO, 2007; ALVES, 2008; FIALHO, 2008))

Dentre as ferramentas expostas, a mais utilizada pelos docentes e discentes foi o fórum. Segundo Cunha e Paiva (2003), os fóruns facilitam a integração dos participantes e o hábito do trabalho aberto e exposto, oportunizando ao professor uma visão geral dos interesses e empenho dos alunos, bem como a evolução da aprendizagem. Maciel et al. (2012) corroboram destacando que os fóruns são espaços que possibilitam a discussão e a troca de ideias, favorecendo, assim, a construção coletiva do conhecimento.

Outro recurso amplamente utilizado pelos docentes, tanto em contextos de ensino quanto de aprendizagem, foi o vídeo. Isso se deve ao fato de que os vídeos são úteis para despertar o interesse e a curiosidade dos alunos, uma vez que, de 
acordo com Moran (1995), utilizá-los é partir do visível, tornando o assunto abordado mais próximo dos discentes. Trindade, Rehfeldt e Marchi (2016) complementam esta ideia, destacando que os vídeos "normalmente resumem os conteúdos de forma prática e divertida, auxiliando a motivação acerca do tema" (Ibid, 2016, p. 4).

Além dos vídeos, os docentes utilizaram animações para romper com a linearidade com que os conteúdos foram abordados e instigar nos alunos uma maior predisposição para a aprendizagem. Para Kenski (2015), a imagem, o som e o movimento oferecem informações mais realistas ao sujeito que está sendo ensinado, contribuindo para o aprendizado e aprofundamento do conteúdo estudado.

Outra mídia digital inserida nos materiais disponíveis no AVEA foi o infográfico, que, de acordo com Módolo (2007), é um termo derivado da expressão em inglês informational graphics, que significa gráficos informativos. Segundo a autora, esta é uma mídia que alia texto e imagem com o intuito de passar uma mensagem visualmente atrativa para o leitor. A autora destaca, ainda, que os infográficos são recursos de comunicação que transmitem sua mensagem por meio de elementos visuais juntamente com o texto verbal reduzido, além de serem a porta de entrada para outros textos, já que estão no primeiro nível de leitura.

Em complemento aos recursos e mídias digitais disponibilizados no AVEA, os docentes utilizaram o jogo comercial SimCity, um simulador em que o jogador constrói e administra uma cidade. Os pesquisadores decidiram por utilizar este jogo em virtude da possibilidade de os estudantes poderem construir uma cidade onde houvesse uma usina nuclear. Adiciona-se a isso o fato de o jogo ser atrativo e familiar aos estudantes inseridos na turma em que a prática foi realizada. Além de ratificar esta afirmação, Alves (2008) defende que, quando explorado de maneira correta, o jogo comercial pode ser uma ferramenta pedagógica que produz resultados significativos.

Outro autor que defende a utilização de jogos comerciais em contextos de ensino e de aprendizagem é Fialho (2008), cujo trabalho destaca que os jogos são importantes porque "promovem situações de ensino-aprendizagem e aumentam a construção do conhecimento, introduzindo atividades lúdicas e prazerosas, desenvolvendo a capacidade de iniciação e ação ativa e motivadora" (Ibid, 2008, p. 12299). Para Alves (2008), os jogos possibilitam ao jogador "criar caminhos e cenários inexistentes, utilizando os conteúdos que permeiam o seu imaginário para construir narrativas que não estão definidas, imergindo em um universo de histórias" (ALVES, 2008, p. 5).

Neste momento, com base no referencial teórico exposto, cabe apresentar o detalhamento da metodologia utilizada pelos docentes para o desenvolvimento das atividades.

\section{METODOLOGIA UTILIZADA}

Como forma de fundamentar a metodologia utilizada no presente trabalho, os pesquisadores utilizaram como referencial terórico a obra de Silveira e Córdova (2009), na qual realizam uma revisão de literatura quanto às metodologias de pesquisa existentes. No entendimento dos pesquisadores, estes autores fornecem subsídios o suficiente para que este trabalho seja caracterizado como uma 
pesquisa de cunho qualitativo. Para Silveira e Córdova (2009), em uma pesquisa qualitativa o foco não é a representatividade numérica, e sim a análise dos aspectos da realidade, buscando a compreensão e a explicação dos fatos. Além disso, os pesquisadores optaram por trazer, neste trabalho, os resultados e discussões como um relato de experiência.

Como instrumentos de coletas de dados, os pesquisadores utilizaram um diário de bordo compartilhado entre os docentes e os dados gerados pelos estudantes por meio da iteração com os conteúdos e atividades disponibilizados no Ambiente Virtual de Ensino e de Aprendizagem. A pesquisa foi realizada na disciplina de Química, com os alunos do 1o ano do Ensino Médio (EM), no Colégio Cenecista Mário Quintana, localizado no município de Encantado - RS. A turma é formada por 17 alunos, com idades entre 15 e 16 anos.

As atividades desenvolvidas com a utilização do AVEA foram extraclasse e os conteúdos abordados ocorreram a distância. O tema explorado no decorrer da atividade foi Radioatividade, sendo disponibilizado aos alunos um tópico semanal, o que totalizou cinco encontros. Antes de iniciar as atividades semanais, os docentes reuniram os alunos no auditório da escola para uma breve explanação quanto aos objetivos e atividades propostas. Aproveitou-se o momento para demonstrar como acessar o AVEA e realizar estas atividades.

Já o primeiro encontro a distância, "Papo inicial sobre Radioatividade", teve como objetivo compreender porque alguns átomos são radioativos e diferenciar os tipos de radiação. Para tanto, disponibilizou-se o roteiro de estudos "Átomos, isótopos e radioatividade", elaborado por Kare Kullerud, da Universidade de Tronso, Noruega. Em seguida, foram solicitadas aos alunos a realização de uma pesquisa sobre meia vida e decaimento radioativo e a postagem de um resumo sobre o que compreenderam em um fórum de perguntas e respostas. Ainda neste tópico, foi disponibilizada, como material complementar, uma animação do Laboratório Didático Virtual ${ }^{2}$ (LabVir) sobre Raio X, que tem por finalidade explicar o funcionamento do Raio $X$ e, de maneira geral, dos demais tipos de radiação. Ao final da animação, os alunos deveriam responder a cinco questões sobre o assunto estudado. A Figura 1 apresenta a organização do AVEA utilizada pelos docentes no primeiro encontro.

Figura 1 - Organização dos materiais do encontro 1 no AVEA

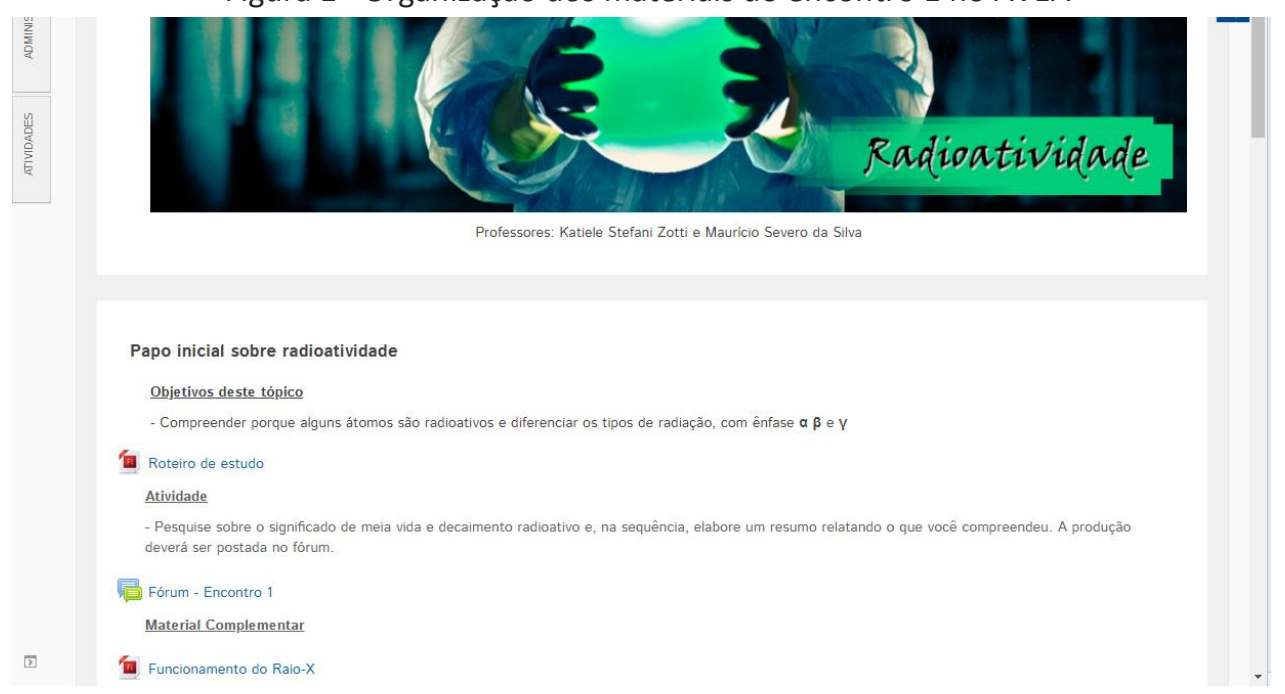

(Fonte: Elaborado pelos autores) 
O segundo encontro, "Níveis de radiação e seus efeitos", teve como objetivo analisar os níveis de radiação aos quais estamos submetidos e seus efeitos no organismo. Para atender a este objetivo, os docentes criaram dentro do Ambiente Virtual um roteiro de estudos formado por mídias digitais extraídas da internet e um vídeo elaborado pelos autores. Na primeira seção do roteiro, foi disponibilizado aos alunos o vídeo "Os locais mais radioativos da Terra", que explana sobre os níveis de radiação a que estamos expostos diariamente, assim como a radiação em diversos lugares da Terra. Na sequência, a seção 2 apresentou um infográfico ${ }^{3}$ que busca quantificar os níveis de radiação a que estamos submetidos. Na seção 3, outro infográfico ${ }^{4}$ foi utilizado para demonstrar os efeitos causados por cada nível de radiação no organismo. Para finalizar o roteiro de estudos, os docentes disponibilizaram um vídeo por eles gravado que abria a discussão sobre uma reportagem ${ }^{5}$ realizada na cidade de Encantado, pela RBS TV. A notícia abordava medições, aferidas no município, de radioatividade, cujos valores encontrados seriam considerados anormais.

Neste segundo encontro, após realizar o roteiro de estudos, os alunos foram convidados a discutir, em um fórum geral, os níveis de radiação encontrados na cidade de Encantado, elaborando uma síntese comparativa entre os dados disponibilizados no infográfico com as informações apresentadas na reportagem. Foi solicitado, também, que os discentes elencassem os tipos de radiação aos quais estão submetidos, seus efeitos no organismo e quais as prováveis fontes de radiação encontradas na cidade.

Já o terceiro encontro, "Simcity e um desastre nuclear", teve por objetivo observar os impactos causados por um desastre nuclear com o auxílio do jogo Simcity ${ }^{6}$, que é um simulador de cidades no qual os estudantes desempenharam a função de prefeito. A atividade deste encontro consistia em construir uma cidade com uma usina nuclear, conduzindo-a a entrar em colapso para, então, observar os efeitos da radiação emitidos na cidade em diferentes situações, como na energia, água, saúde da população, ambiente. Para os discentes que não possuíam o jogo, foi disponibilizado um gameplay ${ }^{7}$ do jogo com uma situação semelhante a que deveriam ocasionar. Na sequência, os alunos elaboraram individualmente um relato dos impactos observados, procurando refletir se, em uma situação real, os efeitos seriam os mesmos. O relatório foi postado na "Tarefa", ferramenta disponível no AVEA. A Figura 2 apresenta duas capturas de tela do gameplay disponibilizado aos alunos, sendo, ao lado esquerdo, a cidade em modo normal de jogo e, à direita, no modo medidor de poluição radioativa.

Figura 2 - Cidade do SimCity cujo reator nuclear entrou em colapso

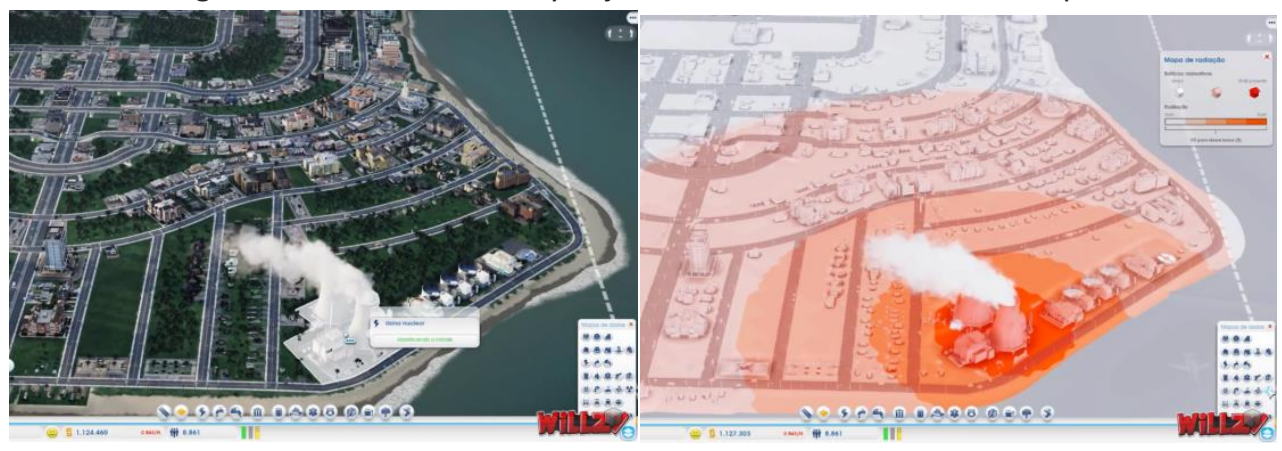

(Fonte: Elaborado pelos autores por meio de capturas de tela do vídeo https://youtu.be/PHh2EmMTYvw) 
Dando continuidade às atividades, o quarto encontro, denominado "Energia Nuclear", teve como objetivo demonstrar a importância e os possíveis riscos da energia nuclear. Para tanto, foi disponibilizado aos alunos um roteiro de estudos contendo três vídeos e um infográfico. O primeiro vídeo, intitulado "Ciclo do Urânio", produzido pela Indústria Nuclear do Brasil (INB), relata o ciclo do combustível nuclear, ou seja, como o urânio contido em um minério transformase em energia. Trata-se de uma animação de aproximadamente cinco minutos no qual a INB percorre todo o processo de tratamento do urânio, desde sua extração até a produção de energia elétrica.

Os outros dois vídeos desta unidade se intitulam "A vida no entorno da mina de Urânio", mina está localizada na cidade de Caetité, na Bahia. Os vídeos mencionados demonstram os diferentes pontos de vista sobre a exploração da mina: a dos empreendedores, que ressaltam as melhorias realizadas na comunidade e o crescimento econômico da cidade, e a dos moradores do entorno da mina, que destacam os impactos ambientais aos quais foram submetidos com a extração do Urânio.

Em complemento aos vídeos, o infográfico apresentado neste encontro destaca o caminho dos resíduos radioativos, desde a sua mineração até a produção de energia. Ao final do roteiro de estudos, os alunos elaboraram um resumo discutindo a importância da energia nuclear, os desastres que já ocorreram e quais seriam as maneiras para evitar futuras catástrofes.

A fim de finalizar as atividades propostas para o estudo sobre radioatividade, no quinto encontro, os alunos formaram pequenos grupos e tiveram como atividade elaborar um vídeo em que foram convidados a demonstrar o que aprenderam sobre a temática em estudo. $\mathrm{O}$ estilo de vídeo ficou à critério de cada grupo.

Posto isso, cabe apresentar os resultados e discussões resultantes da prática pedagógica exposta.

\section{RESULTADOS E DISCUSSÕES}

Os ambientes virtuais de aprendizagem são espaços fecundos e estratégicos, nos quais tem-se a possibilidade de desenvolver a postura autônoma do aluno. No entanto, Messa (2010) destaca que a qualidade do processo educativo depende do envolvimento do aprendiz. Nesse sentido, procurou-se observar como os discentes se envolveram e participaram das atividades propostas. Além disso, cabe esclarecer que, nesta pesquisa, não se buscou desvelar a contribuição individual de cada mídia digital utilizada e, sim, a forma como os estudantes interagiram com o conjunto de mídias e como reagiram quando expostos ao processo de ensino a distância.

Posto isso, quanto à participação dos alunos nos fóruns, os docentes observaram diferentes tipos de interação. Inicialmente, por não estarem habituados com propostas de trabalho deste cunho, a participação e o cuidado com as datas estabelecidas ficou a desejar, porém, no decorrer das semanas, o envolvimento e empenho aumentou. No fórum de perguntas e respostas, no qual os estudantes precisavam fazer uma postagem antes de ter acesso aos comentários dos colegas, os alunos não interagiram entre si. No entanto, todos postaram o resumo solicitado e complementaram com gráficos e outras sugestões 
de leituras para o aprofundamento da temática. Já nos fóruns gerais, que são espaços onde é possível trocar mensagens livremente, os alunos demonstraram maior envolvimento e interagiram com mais frequência, contribuindo com colocações, sugestões e opiniões. Vale ressaltar que os fóruns estavam sendo monitorados, e, sempre que era pertinente, os docentes realizaram questionamentos, convidando-os, assim, para debaterem novas ideias.

Ainda quanto aos fóruns, um, em particular, chamou a atenção dos docentes. O fórum relativo à discussão sobre os níveis de radiação encontrados na cidade onde vivem os estudantes foi o que mais recebeu postagens, 28 no total. Este número representa quase $50 \%$ das postagens realizadas durante o período no qual a prática foi realizada. Para os docentes, existem dois fatores que podem ter influenciado para que houvesse este número expressivo de mensagens. Primeiro, o vídeo que provocou a discussão foi o único produzido pelos docentes abordando o conteúdo em estudo. Segundo, o fato de os professores terem utilizado como cenário de discussão a cidade na qual tanto docentes quanto discentes residem.

Além disso, neste fórum em específico, alguns estudantes reagiram a uma postagem na qual uma aluna utilizou erroneamente um conceito. Em suas postagens, os colegas a auxiliaram a compreender o porquê de sua colocação ser problemática, contribuindo para o aprendizado da aluna. Para os docentes envolvidos, estas mensagens evidenciam quão ricas são as interações realizadas entre os estudantes por meio da ferramenta Fórum do Ambiente Virtual e confirmam o pensamento de Maciel et al. (2012) e Cunha e Paiva (2003) sobre este recurso.

Mesmo com o sucesso apresentado durante as discussões nos fóruns, foi a atividade envolvendo o jogo que mais mobilizou e envolveu os alunos. Como a atividade foi extraclasse e a distância, a docente titular da turma utilizava as aulas presenciais para abordar outros conteúdos, ainda assim, foi perceptível o envolvimento e discussões dos alunos. No decorrer da semana, observou-se uma atenção especial a esta atividade, uma vez que o assunto em sala de aula girou em torno do nível em que se encontravam e dos avanços que apresentavam. Este fato está em consonância com a colocação de Fialho (2008), na qual destaca que, ao jogar, o indivíduo se depara com a vontade de vencer, provocando assim uma sensação agradável, visto que os desafios são situações que mexem com o emocional das pessoas. No entanto, a tarefa na qual deveriam elaborar um relatório sobre os impactos observados durante a interação com o jogo teve baixa adesão, dado que poucos alunos postaram a atividade solicitada. Quando indagados sobre o motivo da não postagem, a resposta foi o acúmulo de atividades escolares próximas ao período de entrega do relatório. Ainda assim, mesmo com a prorrogação do prazo, poucos estudantes finalizaram a tarefa.

Já a elaboração do vídeo, no qual deveriam explanar alguns dos assuntos abordados durante o período de estudos, evidenciou a preferência dos alunos por atividades envolvendo a produção de vídeos. A criação deste material possibilitou aos discentes trabalharem de forma autônoma, uma vez que, de acordo com Demo (2016, texto digital), o que interessa "é como o estudante faz o vídeo, tornando-se autor do conteúdo, não seu consumidor". Além disso, os docentes surpreenderamse com a qualidade do material elaborado pelos estudantes e com suas habilidades de interpretação e intimidade com a tecnologia e formato de mídia utilizado. Este resultado corrobora com a tese defendida por Prensky $(2001$, p. 1$)$ de que as novas gerações são fluentes na "linguagem digital dos computadores, vídeo games e 
internet". Posto isso, os professores sugerem aos leitores deste trabalho que assistam a um dos vídeos produzidos pelos estudantes, cujo link está disponível na Figura 3.

Figura 3- Estudante interpretando um aluno que está coletando informações para seu trabalho de conclusão de curso

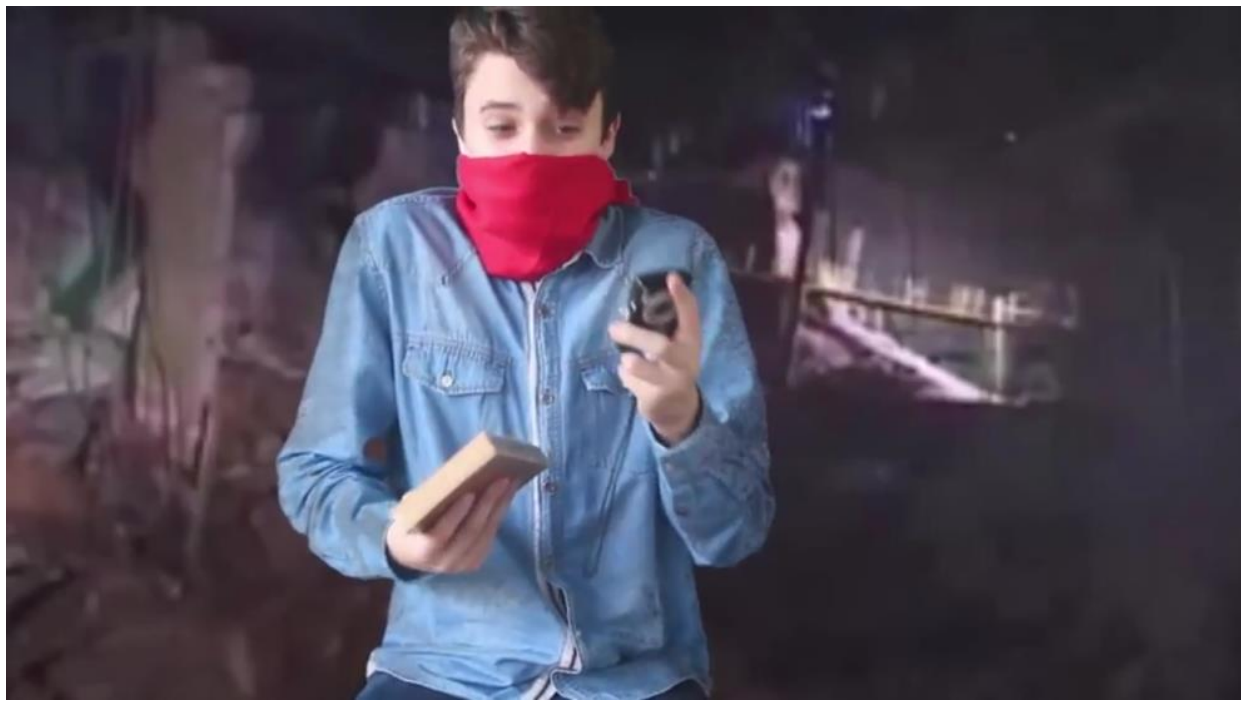

(Fonte: Elaborado pelos autores por meio de captura de tela do vídeo https://youtu.be/OYJ2-6--qB8)

\section{CONSIDERAÇÕES FINAIS}

Diante dos resultados obtidos, os docentes possuem indícios para acreditar que a prática realizada atingiu seu objetivo, que foi desvelar os efeitos de diferentes mídias digitais por meio de um Ambiente Virtual de Ensino e Aprendizagem, com discentes do 1 o ano do Ensino Médio, na disciplina de Química. Quanto à expectativa dos docentes, esta foi superada. O uso da educação a distância, com o suporte do Ambiente Virtual de Ensino e Aprendizagem, associado ao uso de um leque variado de mídias digitais, possibilitou aos estudantes experienciarem uma prática diferente da qual estão acostumados. Ainda assim, adequaram-se ao formato proposto e responderam bem à grande maioria das atividades propostas.

Existem dois pontos a serem considerados que contribuíram para o sucesso obtido nesta empreitada. $O$ primeiro deles é o fato de que os docentes, além de trabalharem de forma colaborativa, tiveram tempo para planejar, discutir e refletir sobre todas as etapas que a prática pedagógica seguiria. O segundo é que as barreiras quanto ao uso das tecnologias digitais descritas por Prensky (2001) puderam ser superadas em virtude de ambos os docentes estarem desenvolvendo pesquisas relativas ao uso de tecnologias em âmbito educacional, sendo um deles profissional da área tecnológica como experiência em educação a distância e o outro, uma professora que constantemente atualiza suas práticas, buscando inserir as mídias digitais em contextos de ensino e de aprendizagem.

Como nem tudo é perfeito, surgiram também alguns pontos para reflexão dos docentes. O primeiro está relacionado ao uso da ferramenta fórum configurada para perguntas e respostas. Este modelo de fórum produziu diversas respostas 
semelhantes dos alunos e pouca interação entre eles. Com isso, seu funcionamento aproximou-se muito mais de um questionário do que o de um fórum, uma vez que cada estudante apenas depositou suas respostas, sem reflexão, discussão ou questionamentos quanto às respostas dos demais colegas. O segundo ponto que cabe reflexão é o fato de que, mesmo havendo um grande envolvimento dos alunos na atividade relacionada ao jogo SimCity, poucos alunos concluíram o relatório solicitado ao final da proposta. Em relação a isso, ficam alguns questionamentos: mesmo que os alunos não tenham escrito o relatório solicitado, eles fizeram a reflexão proposta pela atividade ou apenas utilizaram o jogo como forma de entretenimento? Será que a escolha do relatório como resultado final da atividade foi a mais adequada? Um terceiro ponto para reflexão surgiu em virtude de a atividade relativa ao jogo ter sido planejada de modo que os pais/responsáveis dos alunos pudessem participar e envolverem-se na elaboração do relatório, o que, de fato, não ocorreu. Quanto a isso, cabe salientar que os docentes entraram em contato com os familiares dos estudantes e os convidaram para participar da atividade, tendo, alguns, acenado positivamente. Além disso, os docentes gravaram um vídeo explicando como a atividade ocorreria e encaminharam aos pais que, inicialmente, haviam aceitado participar. Diante disso, adiciona-se uma nova questão para reflexão quanto ao ponto anterior: será que o não envolvimento dos pais fez com que os estudantes desistissem de entregar o relatório?

Como contribuição para os estudos na área de ensino, os autores destacam que existem indicativos nesta investigação para afirmar que a educação a distância, associada a um Ambiente Virtual de Ensino e de Aprendizagem e às mídias digitais, pode ser utilizada como um recurso que permite ao docente experimentar práticas pedagógicas que extrapolem o espaço físico da sala de aula ou da escola. Neste sentido, é possível citar como indícios a adesão dos estudantes ao fórum de discussão relacionado ao vídeo produzido pelos docentes e a produção do vídeo autoral por parte dos alunos. Neste último, em especial, fica evidente que os estudantes se apropriaram dos conceitos trabalhados durante os encontros a distância.

Por fim, os autores gostariam de destacar que o uso de mídias digitais e dos diversos tipos de tecnologias em sala de aula pode colaborar para que o ensino de algumas matérias, como o da química, seja menos tedioso, além de contribuir para que o aprendizado seja efetivamente significativo. Assim, cabe aos docentes que utilizam estes recursos o papel de incentivar e estimular outros professores a usufruírem de tecnologias e mídias digitais em sala de aula, divulgando suas experiências, compartilhando resultados e, se necessário, auxiliando no planejamento e execução de práticas empíricas, como a relatada neste trabalho. 


\title{
The use of digital media, associated to the virtual environment of teaching and learning, in the teaching of chemistry: exploring radioactivity through distance education
}

\begin{abstract}
The present text is a experience report witch had the objective of making possible to high school students approach the study of radiation using an Learning Management System. The teachers organized the pedagogical practice in six meetings, one presential and the followings remotely. The teachers made use of digital medias as: animations, videos, text, infographics and the comercial game Simcity, as well as a internal comunication and integration tool and the discussion forum present in the LMS. This resource made possible the integration of the students, providing rich and heated discussions. However, SimCity caused the most engagement in the group. As the evaluation method, the teachers requested the students to form groups and produce a video, presenting what they learned about the subject. The quality of the content and production presented by the students surprised the teachers and made evident the preference on this kind of activity. The teachers belive that the strategic use of LMS and digital medias together with activities that make possible the students to be authors of their own discussions, reflections and videos helped in the development of a more proactive position and a bigger autonomy on their studies.
\end{abstract}

KEYWORDS: Experience report. Pedagogical practice. Distance learning. Virtual learning environment. Digital media. 
1 Centro Regional de Estudos sobre o Desenvolvimento da Sociedade da Informação (Cetic.br) do Núcleo de Informação e Coordenação do Ponto BR (NIC.br) - http://cetic.br/

2 Segundo Leite (2016), no LabVir ou Laboratório Didático Virtual, encontram-se várias páginas com material didático, bem como questões elaboradas por especialistas da área. Um dos objetivos do laboratório é incentivar o pensamento e uso do método científico, além de estimular o gosto pela ciência. O LabVir pode ser acessado pelo link: <www.labvirt.fe.usp.br>

30 infográfico utilizado foi extraído do site <http://n.i.uol.com.br/ultnot/1103/radioativo.jpg>

40 infográfico utilizado foi extraído do site <https://i2.wp.com/diariodebiologia.com/wpcontent/uploads/sites/4/2015/09/radiac3a7c3a3o-noorganismo.jpg?resize $=635 \% 2$ C478\&ssl $=1>$

5 A reportagem da RBS TV sobre a radiação encontrada na cidade de Encantado RS está disponível em: <https://www.youtube.com/watch?v=mNVLoiyXgXI>

60 Simcity é um jogo no qual o objetivo é que o jogador crie e gerencie recursos de uma cidade virtual. Uma de suas características é não possuir um fim, podendo ser jogado por tempo indeterminado. Trata-se de um jogo comercial produzido pela empresa Eletronic Arts e está disponível para a compra no site dos desenvolvedores.

7 Gameplay é um formato de vídeo no qual os jogadores gravam e comentam suas ações enquanto jogam e, posteriormente, os publicam na Internet. O objetivo destes vídeos é aproximar o público que compartilha o gosto por jogos digitais. Além disso, uma estratégia dos desenvolvedores de jogos é liberar seus últimos lançamentos para os produtores deste tipo de conteúdo, fazendo com que outras pessoas conheçam seus jogos e os comprem.

\section{REFERÊNCIAS}

ALVES, Lynn. Relações entre os jogos digitais e aprendizagem: delineando percurso. Educação, Formação \& Tecnologias-ISSN 1646-933X, v. 1, n. 2, p. [310], 2008. Disponível em:

$<$ http://eft.educom.pt/index.php/eft/article/view/58/38>. Acesso em: 20 mai. 2017.

CETIC.BR (Brasil). TIC Educação. 2016. Disponível em:

<http://cetic.br/pesquisa/educacao/>. Acesso em: 02 jan. 2017.

CUNHA, Fernando; PAIVA, João. A utilização de fóruns em contexto de Ensino/aprendizagem. In: Actas da III Conferência Internacional sobre 
DEMO, Pedro. Metodologias Ativas: Estratégias para salvar a aula. 2016.

Disponível em:

<https://docs.google.com/document/u/1/d/1BTuNMXyuN7uWxKY3EldMRFWFYt EhMQuGicStGXs-9_Q/pub>. Acesso em: 05 dez. 2016.

FIALHO, Neusa Nogueira. Os jogos pedagógicos como ferramentas de ensino. In: Congresso Nacional de Educação. 2008. p. 12298-12306. Disponível em: http://www.pucpr.br/eventos/educere/educere2008/anais/pdf/293 114.pdf> Acesso em: 24 mai. 2017.

Indústria Nucleares do Brasil. Ciclo do Urânio. Disponível em: <https://www.youtube.com/watch?v=eWV1JVrR oU >. Acesso em: 25 nov. 2016.

CAETITE/BA 2014 - INB. Disponível em:

<https://www.youtube.com/watch?v=zCofeK zS64> . Acesso em: 25 nov. 2016.

KENSKI, Vani Moreira. Educação e tecnologias: o novo ritmo da informática. Campinas, SP: Papirus, 2015. E-book.

KULLERUD,Kare. Átomos, isótopos e radioatividade. Universidade do Tromso, Noruega. Disponível em: <http://webgeology.alfaweb.no/webgeology files/brazil/atoms iso bra.swf>. Acesso em: 25 nov. 2016.

LAMES, Liliane da Costa Jacobs. Docência no ensino superior: o uso das mídias digitais como estratégia pedagógica. 2011. 159 f. Dissertação (Mestrado) - Curso de Mestrado em Ciências Contábeis, 1 Fundação Escola de Comércio Álvares Penteado - Fecap, São Paulo, 2011. Disponível em: <http://tede.fecap.br:8080/jspui/bitstream/tede/494/1/Liliane_da_Costa_Jacobs _Lames.pdf>. Acesso em: 15 mai. 2017.

LEITE, Bruno Silva. Discussões sobre Ambientes Pessoais de Aprendizagem. Educaonline, Rio de Janeiro, v. 10, n. 1, p.37-54, jan./abr. 2016. Quadrimestral. Disponível em:

<http://www.latec.ufrj.br/revistas/index.php?journal=educaonline\&page=article \&op=view\&path;[]=809\&path;[]=738>. Acesso em: 05 mai. 2017.

MACIEL, Cristiano et al (Org.). Ambientes Virtuais de Aprendizagem. Cuiabá: Edufmt, 2012. 262 p. Disponível em: $<$ https://edisciplinas.usp.br/pluginfile.php/129865/mod resource/content/1/Am bientes\%20Virtuais.pdf >. Acesso em: 18 mai. 2017. 
MESSA, Wilmara Cruz. Utilização de ambientes virtuais de aprendizagem-AVAs: a busca por uma aprendizagem significativa. Revista brasileira de aprendizagem aberta e a distância, v. 9, p. 8, 2010. Disponível em:

$<$ http://www.abed.org.br/revistacientifica/Revista PDF Doc/2010/2010 246201 0174147.pdf>. Acesso em: 25 mai. 2017.

MÓDOLO, Cristiane Machado. Infográficos: características, conceitos e princípios básicos. In: XII Congresso Brasileiro de Ciências da Comunicação da Região Sudeste. 2007. Disponível em: $<$ http://ddiprojeto2.xpg.uol.com.br/infograficos caracteristicas conceitos e pri ncipios basicos.pdf >. Acesso em: 25 mai. 2017.

MORAN, José Manuel. O vídeo na sala de aula. Comunicação \& Educação, n. 2, p. 27-35, 1995. Disponível em:

<http://www.eca.usp.br/prof/moran/site/textos/desafios pessoais/vidsal.pdf $>$. Acesso em 18 mai. 2017.

PRENSKY, Marc. Digital Natives, Digital Immigrants. On the Horizon, v. 9, n. 5, p. 1-6, 2001. Disponível em: <http://www.marcprensky.com/writing/Prensky\%20\%20Digital\%20Natives,\%20Digital\%20lmmigrants\%20-\%20Part1.pdf>. Acesso em: 18 mai. 2017.

SAEED, Nauman. Integration and acceptance of Web 2.0 technologies in higher education. 2010. $200 \mathrm{f}$. Tese (Doctor of Philosophy) - Melbourne, Swinburne University of Technology, 2010. Disponível em:

<http://researchbank.swinburne.edu.au/vital/access/manager/Repository/swin:1 8535>. Acesso em: 17 out. 2016.

SANTOS, Simone Andrade et al. Uso pedagógico do ambiente virtual de aprendizagem Moodle como apoio a aula presencial. Revista EDaPECI, [S.I.], v. 16, n. 1, p. 78-94, abr. 2016. ISSN 2176-171X. Disponível em: $<$ https://seer.ufs.br/index.php/edapeci/article/view/3897>. Acesso em: 20 mai. 2017.

SILVEIRA, Denise Tolfo. CÓRDOVA, Fernanda Peixoto. Unidade 2 - A pesquisa científica. In: GERHARDT, Tatiana Engel. SILVEIRA, Denise Tolfo. Métodos de Pesquisa. POA: Editora da UFRGS, 2009. Disponível em: <http://www.ufrgs.br/cursopgdr/downloadsSerie/derad005.pdf>. Acesso em: 23 mai. 2017.

TRINDADE, Kelli Cristina Freitas; REHFELDT, Marcia Jussara Hepp; MARCHI, Miriam. Ambiente Virtual de Aprendizagem: repaginando antigas práticas pedagógicas. Disponível em: <http://tecedu.pro.br/wpcontent/uploads/2016/09/REL3-ano8-vol17-dez2016.pdf>. Acesso em: 20 mai. 2017. 
TV Zabelê. INB: a vida no entorno da mina de urânio. Disponível em: <https://www.youtube.com/watch?v=69KhzmY-DY0>. Acesso em: 25 nov. 2016.

Veritasium. Os lugares mais radioativos da Terra. Disponível em:

<https://www.youtube.com/watch?v=TRL7o2kPqw0>. Acesso em: 25 nov. 2016.

\section{Recebido: 2017-11-06 \\ Aprovado: 2018-08-29}

DOI: $10.3895 /$ rbect.v12n2.7296

Como citar: SILVA, M. S.; ZOTTI, K. S.; REHFELDT, M. J. H.; MARCHI, M. I. O uso de mídias digitais, associados ao ambiente virtual de ensino e de aprendizagem, no ensino de química: explorando a radioatividade por meio da educação a distância. Revista Brasileira de Ensino de Ciência e Tecnologia, v. 12, n. 2, 2019. Disponível em: <https://periodicos.utfpr.edu.br/rbect/article/view/7296>. Acesso em: xxx. Correspondência: Maurício Severo da Silva - mss@universo.univates.br Direito autoral: Este artigo está licenciado sob os termos da Licença Creative Commons-Atribuição 4.0 Internacional.

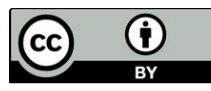

